\title{
Strong Convergence Iterative Algorithms for Equilibrium Problems and Fixed Point Problems in Banach Spaces
}

\author{
Shenghua Wang ${ }^{1}$ and Shin Min Kang ${ }^{2}$ \\ ${ }^{1}$ Department of Applied Mathematics and Physics, North China Electric Power University, Baoding 071003, China \\ ${ }^{2}$ Department of Mathematics and RINS, Gyeongsang National University, Jinju 660-701, Republic of Korea
}

Correspondence should be addressed to Shin Min Kang; smkang@gnu.ac.kr

Received 1 February 2013; Accepted 9 March 2013

Academic Editor: Yisheng Song

Copyright (c) 2013 S. Wang and S. M. Kang. This is an open access article distributed under the Creative Commons Attribution License, which permits unrestricted use, distribution, and reproduction in any medium, provided the original work is properly cited.

We first introduce the concept of Bregman asymptotically quasinonexpansive mappings and prove that the fixed point set of this kind of mappings is closed and convex. Then we construct an iterative scheme to find a common element of the set of solutions of an equilibrium problem and the set of common fixed points of a countable family of Bregman asymptotically quasinonexpansive mappings in reflexive Banach spaces and prove strong convergence theorems. Our results extend the recent ones of some others.

\section{Introduction}

Let $E$ be a real reflexive Banach space with norm $\|\cdot\|$ and $E^{*}$ the dual space of $E$ equipped with the inducted norm $\|\cdot\|_{*}$. Throughout this paper, $f: E \rightarrow(-\infty,+\infty]$ is a proper, lower semicontinuous, and convex function and the Fenchel conjugate of $f$ is the function $f^{*}: E^{*} \rightarrow(-\infty,+\infty]$ defined by

$$
f^{*}(\xi)=\sup \{\langle\xi, x\rangle-f(x): x \in E\} .
$$

We denote by $\operatorname{dom} f$ the domain of $f$, that is, the set $\{x \in$ $E: f(x)<+\infty\}$.

Let $C$ be a nonempty, closed, and convex subset of $E$ and $T: C \rightarrow C$ a nonlinear mapping. The fixed points set of $T$ is denoted by

$$
F(T)=\{x \in C: x=T x\} .
$$

Recall that a mapping $T: C \rightarrow C$ is said to be nonexpansive if, for each $x, y \in C$,

$$
\|T x-T y\| \leq\|x-y\| .
$$

Nakajo-Takahashi [1] introduced the following hybrid method which is the so-called CQ-method for a nonexpansive mapping $T$ in a Hilbert space $H$ :

$$
\begin{gathered}
x_{0} \in C, \\
y_{n}=\alpha_{n} x_{n}+\left(1-\alpha_{n}\right) T x_{n}, \\
C_{n}=\left\{z \in C:\left\|y_{n}-z\right\| \leq\left\|x_{n}-z\right\|\right\}, \\
Q_{n}=\left\{z \in C:\left\langle x_{n}-z, x_{0}-x_{n}\right\rangle \geq 0\right\}, \\
x_{n+1}=P_{C_{n} \cap Q_{n}} x_{0}, \quad \forall n \geq 0,
\end{gathered}
$$

where $\left\{\alpha_{n}\right\} \subset[0,1]$ and $P_{K}$ is the metric projection from $H$ onto a closed and convex subset $K$ of $H$. They proved that the sequence $\left\{x_{n}\right\}$ generated by (4) converges strongly to a fixed point of $T$ under suitable conditions.

Takahashi et al. [2] introduced a new hybrid iterative scheme called the shrinking projection method for a nonexpansive mapping $T$ in a Hilbert space $H$ as follows:

$$
\begin{gathered}
x_{0} \in H, \\
C_{1}=C, \\
x_{1}=P_{C_{1}} x_{0},
\end{gathered}
$$




$$
\begin{gathered}
y_{n}=\alpha_{n} x_{n}+\left(1-\alpha_{n}\right) T x_{n}, \\
C_{n+1}=\left\{z \in C_{n}:\left\|y_{n}-z\right\| \leq\left\|x_{n}-z\right\|\right\}, \\
x_{n+1}=P_{C_{n+1}} x, \quad \forall n \geq 1,
\end{gathered}
$$

where $\left\{\alpha_{n}\right\} \subset[0,1]$, and they proved that the sequence $\left\{x_{n}\right\}$ generated by (5) converges strongly to a fixed point of $T$ under suitable conditions.

In 2010, Reich and Sabach [3] introduced the following two hybrid iterative schemes for Bregman strongly nonexpansive mappings $T_{i}: E \rightarrow E(i=1,2, \ldots, N)$ in a reflexive Banach space $E$ :

$$
\begin{gathered}
x_{0} \in E \\
y_{n}^{i}=T_{i}\left(x_{n}+e_{n}^{i}\right), \\
C_{n}^{i}=\left\{z \in E: D_{f}\left(z, y_{n}^{i}\right) \leq D_{f}\left(z, x_{n}+e_{n}^{i}\right)\right\}, \\
C_{n}:=\bigcap_{i=1}^{N} C_{n}^{i}, \\
Q_{n}=\left\{z \in E:\left\langle z-x_{n}, \nabla f\left(x_{0}\right)-\nabla f\left(x_{n}\right)\right\rangle \leq 0\right\}, \\
x_{n+1}=P_{C_{n} \cap Q_{n}}^{f}\left(x_{0}\right), \quad \forall n \geq 0, \\
x_{0} \in E, \\
C_{0}^{i}=E, \quad i=1,2, \ldots, N, \\
y_{n}^{i}=T_{i}\left(x_{n}+e_{n}^{i}\right), \\
C_{n+1}^{i}=\left\{z \in C_{n}^{i}: D_{f}\left(z, y_{n}^{i}\right) \leq D_{f}\left(z, x_{n}+e_{n}^{i}\right)\right\}, \\
C_{n+1}:=\bigcap_{i=1}^{i} C_{n+1}^{i}, \\
x_{n+1}=P_{C_{n} \cap Q_{n}}^{f}\left(x_{0}\right), \quad \forall n \geq 0,
\end{gathered}
$$

where $P_{K}^{f}$ is the Bregman projection with respect to $f$ from $E$ onto a closed and convex subset $K$ of $E$. They proved that the sequence $\left\{x_{n}\right\}$ generated by both (6) and (7) converges strongly to a common fixed point of $\left\{T_{i}\right\}_{i=1}^{N}$.

The construction of fixed points for Bregman-type mappings via iterative processes has been investigated in, for example, [4-8].

In this paper, we design a new hybrid iterative scheme for finding a common element of the set of solutions of an equilibrium problem and the set of common fixed points of a countable family of Bregman asymptotically quasinonexpansive mappings in reflexive Banach spaces and prove some strong convergence theorems. Our results extend the recent one of Reich and Sabach [3].

\section{Preliminaries}

Let $E$ be a real Banach space. For any $x \in \operatorname{int} \operatorname{dom} f$ and $y \in E$, we define the right-hand derivative of $f$ at $x$ in the direction $y$ by

$$
f^{o}(x, y):=\lim _{t \rightarrow 0^{+}} \frac{f(x+t y)-f(x)}{t} .
$$

The function $f$ is said to be Gâteaux differentiable at $x$ if $\lim _{t \rightarrow 0^{+}}((f(x+t y)-f(x)) / t)$ exists for any $y$. In this case, $f^{o}(x, y)$ coincides with $\nabla f(x)$, the value of the gradient $\nabla f$ of $f$ at $x$. The function $f$ is said to be Gâteaux differentiable if it is Gâteaux differentiable for any $x \in \operatorname{int} \operatorname{dom} f$. The function $f$ is said to be Fréchet differentiable at $x$ if this limit is attained uniformly in $\|y\|=1$. Finally, $f$ is said to be uniformly Fréchet differentiable on a subset $C$ of $E$ if the limit is attained uniformly for $x \in C$ and $\|y\|=1$.

Let $E$ be a reflexive Banach space. The Legendre function is defined from a general Banach space $E$ into $(-\infty,+\infty$ ) (see [9]). According to [9], the function $f$ is Legendre if and only if it satisfies the following conditions

(L1) The interior of the domain of $f$ (denoted by int $\operatorname{dom} f$ ) is nonempty; $f^{*}$ is Gâteaux differentiable on int $\operatorname{dom} f$ and $\operatorname{dom} \nabla f=\operatorname{int} \operatorname{dom} f$.

(L2) The interior of the domain $f^{*}$ (denoted by int $\operatorname{dom} f^{*}$ ) is nonempty; $f^{*}$ is Gâteaux differentiable on int $\operatorname{dom} f^{*}$ and $\operatorname{dom} \nabla f^{*}=\operatorname{int} \operatorname{dom} f^{*}$.

Since $E$ is reflexive, we always have $(\partial f)^{-1}=\partial f^{*}$ (see $[10])$. This fact, when combined with conditions (L1) and (L2), implies the following equalities:

$$
\begin{gathered}
\nabla f=\left(\nabla f^{*}\right)^{-1}, \\
\operatorname{ran} \nabla f=\operatorname{dom} \nabla f^{*}=\operatorname{int} \operatorname{dom} f^{*}, \\
\operatorname{ran} \nabla f^{*}=\operatorname{dom} \nabla f=\operatorname{int} \operatorname{dom} f .
\end{gathered}
$$

Also, conditions (L1) and (L2), in conjunction with [9], imply that the functions $f$ and $f^{*}$ are strictly convex on the interior of their respective domains. Several interesting examples of the Legendre functions are presented in $[9,11]$. Especially, the functions $(1 / s)\|\cdot\|^{s}$ with $s \in(1, \infty)$ are Legendre, where the Banach space $E$ is smooth and strictly convex and, in particular, a Hilbert space.

Let $f: E \rightarrow(-\infty,+\infty]$ be a convex and Gâteaux differentiable function. The function $D_{f}: \operatorname{dom} f \times \operatorname{int} \operatorname{dom} f \rightarrow$ $[0,+\infty)$ defined as

$$
D_{f}(y, x):=f(y)-f(x)-\langle y-x, \nabla f(x)\rangle
$$

is called the Bregman distance with respect to $f$ [12].

By the definition, we know the following property (the three point identity): for any $x \in \operatorname{dom} f$ and $y, z \in$ int $\operatorname{dom} f$,

$$
\begin{array}{r}
D_{f}(x, y)+D_{f}(y, z)-D_{f}(x, z) \\
=\langle\nabla f(z)-\nabla f(y), x-y\rangle .
\end{array}
$$


Recall that the Bregman projection [13] of $x \in \operatorname{int} \operatorname{dom} f$ onto the nonempty, closed, and convex subset $C$ of $\operatorname{dom} f$ is the necessarily unique vector $\operatorname{proj}_{C}^{f}(x) \in C$ satisfying

$$
D_{f}\left(\operatorname{proj}_{C}^{f}(x), x\right)=\inf \left\{D_{f}(y, x): y \in C\right\} .
$$

Let $f: E \rightarrow(-\infty,+\infty]$ be a convex and Gâteaux differentiable function. The function $f$ is said to be totally convex at $x \in \operatorname{int} \operatorname{dom} f$ if its modulus of total convexity at $x$, that is, the function $v_{f}:$ int $\operatorname{dom} f \times[0,+\infty) \rightarrow[0,+\infty]$ defined by

$$
v_{f}(x, t):=\inf \left\{D_{f}(y, x): y \in \operatorname{dom} f,\|y-x\|=t\right\},
$$

is positive whenever $t>0$. The function $f$ is said to be totally convex when it is totally convex at every point $x \in$ int $\operatorname{dom} f$. In addition, the function $f$ is said to be totally convex on bounded sets if $v_{f}(B, t)$ is positive for any nonempty bounded subset $B$ of $E$ and $t>0$, where the modulus of total convexity of the function $f$ on the set $B$ is the function $v_{f}:$ int $\operatorname{dom} f \times[0,+\infty) \rightarrow[0,+\infty]$ defined by

$$
v_{f}(B, t):=\inf \left\{v_{f}(x, t): x \in B \cap \operatorname{dom} f\right\} .
$$

Some examples of the totally convex functions can be found in $[14,15]$.

Recall that the function $f$ is said to be sequentially consistent [15] if, for any two sequences $\left\{x_{n}\right\}$ and $\left\{y_{n}\right\}$ in $E$ such that the first is bounded,

$$
\lim _{n \rightarrow \infty} D_{f}\left(y_{n}, x_{n}\right)=0 \Longrightarrow \lim _{n \rightarrow \infty}\left\|y_{n}-x_{n}\right\|=0 .
$$

Let $C$ be a nonempty, closed, and convex subset of $E$ and $g: C \times C \rightarrow \mathbb{R}$ a bifunction that satisfies the following conditions:

(C1) $g(x, x)=0$ for all $x \in C$;

(C2) $g$ is monotone, that is, $g(x, y)+g(y, x) \leq 0$ for all $x, y \in C$;

(C3) $\lim \sup _{t \downarrow 0} g(t z+(1-t) x, y) \leq g(x, y)$ for all $x, y, z \in$ $C$;

(C4) for all $x \in C, g(x, \cdot)$ is convex and lower semicontinuous.

The equilibrium problem with respect to $g$ is as follows: find $\bar{x} \in C$ such that

$$
g(\bar{x}, y) \geq 0, \quad \forall y \in C .
$$

The set of all solutions of (16) is denoted by $\operatorname{EP}(g)$. The resolvent of a bifunction $g: C \times C \rightarrow \mathbb{R}[16]$ is the operator $\operatorname{Res}_{g}^{f}: E \rightarrow 2^{C}$ denoted by

$$
\begin{gathered}
\operatorname{Res}_{g}^{f}(x)=\{z \in C: g(z, y)+\langle\nabla f(z)-\nabla f(x), y-z\rangle \\
\geq 0, \forall y \in C\} .
\end{gathered}
$$

For any $x \in E$, there exists $z \in C$ such that $z=\operatorname{Res}_{g}^{f}(x)$; see [3].

Let $K$ be a convex subset of int $\operatorname{dom} f$ and $T: K \rightarrow$ $K$ a mapping. A point $p$ in the closure of $K$ is said to be an asymptotic fixed point of $T[17,18]$ if $K$ contains a sequence $\left\{x_{n}\right\}$ which converges weakly to $p$ such that the strong $\lim _{n \rightarrow \infty}\left(x_{n}-T x_{n}\right)=0$. The set of asymptotic fixed points of $T$ will be denoted by $\widehat{F}(T)$. The mapping $T$ is called Bregman quasi-nonexpansive if $F(T) \neq \emptyset$ and

$$
D_{f}(v, x) \leq D_{f}(v, x), \quad \forall v \in F(T), x \in K .
$$

$T$ is said to be Bregman (quasi)-strongly nonexpansive [6] with respcet to a nonempty $\widehat{F}(T)$ if

$$
D_{f}(p, T x) \leq D_{f}(p, x),
$$

for all $p \in \widehat{F}(T)$ and $x \in K$, and if whenever $\left\{x_{n}\right\} \subset K$ is bounded, $p \in \widehat{F}(T)$, and

$$
\lim _{n \rightarrow \infty}\left(D_{f}\left(p, x_{n}\right)-D_{f}\left(p, T x_{n}\right)\right)=0,
$$

it follows that

$$
\lim _{n \rightarrow \infty} D_{f}\left(T x_{n}, x_{n}\right)=0 .
$$

The mapping $T$ is called Bregman firmly nonexpansive if

$$
\begin{aligned}
& \langle\nabla f(T x)-\nabla f(T y), T x-T y\rangle \\
& \quad \leq\langle\nabla f(x)-\nabla f(y), T x-T y\rangle
\end{aligned}
$$

for all $x, y \in K$.

Next, we introduce a new mapping that is called Bregman asymptotically quasinonexpansive mapping which is a natural extension of Bregman quasinonexpansive mapping introduced by Reich and Sabach [3]. The mapping $T: K \rightarrow$ $K$ is said to be Bregman asymptotically quasi-nonexpansive if there exists a sequence $\left\{k_{n}\right\} \subset[1, \infty)$ satisfying $\lim _{n \rightarrow \infty} k_{n}=$ 1 such that, for every $n \geq 1$,

$$
D_{f}\left(v, T^{n} x\right) \leq k_{n} D_{f}(v, x), \quad \forall v \in F(T), x \in K .
$$

Obviously, every Bregman quasinonexpansive mapping is a Bregman asymptotically quasi-nonexpansive one with $k_{n}=$ 1.

Let $E$ be a Banach space and $C$ a nonempty subset of $E$. The mapping $T: C \rightarrow C$ is said to be uniformly asymptotically regular on $C$ if

$$
\lim _{n \rightarrow \infty}\left(\sup _{x \in C}\left\|T^{n+1} x-T^{n} x\right\|\right)=0 .
$$

The mapping $T$ is said to be closed if, for any sequence $\left\{x_{n}\right\}$ in $C$ such that $\lim _{n \rightarrow \infty} x_{n}=x_{0}$ and $\lim _{n \rightarrow \infty} T x_{n}=y_{0}, T x_{0}=y_{0}$.

The following is an important result which will be used in the next section.

Lemma 1. Let $E$ be a reflexive Banach space and $f: E \rightarrow$ $(-\infty,+\infty)$ a Gâteaux differentiable and Legendre function 
which is totally convex on bounded sets. Let $K$ be a nonempty, closed and convex subset of int $\operatorname{dom} f$ and $T: K \rightarrow K a$ closed Bergman asymptotically quasi-nonexpansive mapping with the sequence $\left\{k_{n}\right\} \subset[1,+\infty)$ such that $k_{n} \rightarrow 1$ as $n \rightarrow \infty$. Then $F(T)$ is closed and convex.

Proof. The closedness of $F(T)$ comes directly from the closedness of $T$. Now, for arbitrary $p_{1}, p_{2} \in F(T), t \in(0,1)$, put $p_{3}=t p_{1}+(1-t) p_{2}$. We prove that $T p_{3}=p_{3}$. Indeed, from the definition of $D_{f}$, we see that

$$
\begin{aligned}
& D_{f}\left(p_{3}, T^{n} p_{3}\right)=f\left(p_{3}\right)-f\left(T^{n} p_{3}\right) \\
& -\left\langle\nabla f\left(T^{n} p_{3}\right), p_{3}-T^{n} p_{3}\right\rangle \\
& =f\left(p_{3}\right)-f\left(T^{n} p_{3}\right) \\
& -\left\langle\nabla f\left(T^{n} p_{3}\right), t p_{1}+(1-t) p_{2}-T^{n} p_{3}\right\rangle \\
& =f\left(p_{3}\right)-f\left(T^{n} p_{3}\right) \\
& -t\left\langle\nabla f\left(T^{n} p_{3}\right), p_{1}-T^{n} p_{3}\right\rangle \\
& -(1-t)\left\langle\nabla f\left(T^{n} p_{3}\right), p_{2}-T^{n} p_{3}\right\rangle \\
& =f\left(p_{3}\right)+t D_{f}\left(p_{1}, T^{n} p_{3}\right) \\
& +(1-t) D_{f}\left(p_{2}, T^{n} p_{3}\right)-t f\left(p_{1}\right) \\
& -(1-t) f\left(p_{2}\right) \\
& \leq f\left(p_{3}\right)+t k_{n} D_{f}\left(p_{1}, p_{3}\right) \\
& +(1-t) k_{n} D_{f}\left(p_{2}, p_{3}\right) \\
& -t f\left(p_{1}\right)-(1-t) f\left(p_{2}\right) \\
& =f\left(p_{3}\right)+k_{n}\left[t \left(f\left(p_{1}\right)-f\left(p_{3}\right)\right.\right. \\
& \left.-\left\langle\nabla f\left(p_{3}\right), p_{1}-p_{3}\right\rangle\right) \\
& +(1-t) \\
& \times\left(f\left(p_{2}\right)-f\left(p_{3}\right)\right. \\
& \left.\left.-\left\langle\nabla f\left(p_{3}\right), p_{2}-p_{3}\right\rangle\right)\right] \\
& -t f\left(p_{1}\right)-(1-t) f\left(p_{2}\right) \\
& =\left(1-k_{n}\right) f\left(p_{3}\right) \\
& +k_{n}\left(t f\left(p_{1}\right)+(1-t) f\left(p_{2}\right)\right) \\
& -t f\left(p_{1}\right)-(1-t) f\left(p_{2}\right) \\
& =\left(k_{n}-1\right)\left(t f\left(p_{1}\right)+(1-t) f\left(p_{2}\right)-f\left(p_{3}\right)\right) \text {. }
\end{aligned}
$$

This implies that $\lim _{n \rightarrow \infty} D_{f}\left(p_{3}, T^{n} p_{3}\right)=0$. It follows from Lemma 3 below that

$$
\lim _{n \rightarrow \infty}\left\|p_{3}-T^{n} p_{3}\right\|=0
$$

that is, $T T^{n} p_{3}-p_{3} \rightarrow 0$ as $n \rightarrow \infty$. In view the closedness of $T$, we can obtain the desired conclusion. This completes the proof.

Finally, we state some lemmas that will used in the proof of main results in next section.

Lemma 2 (see [7]). If $f: E \rightarrow \mathbb{R}$ is uniformly Fréchet differentiable and bounded on bounded subsets of $E$, then $\nabla f$ is uniformly continuous on bounded subsets of $E$ from the strong topology of $E$ to the strong topology of $E^{*}$.

Lemma 3 (see [14]). The function $f$ is totally convex on bounded sets if and only if it is sequentially consistent.

Lemma 4 (see [15]). Suppose that $f$ is Gâteaux differentiable and totally convex on int $\operatorname{dom} f$. Let $x \in \operatorname{int} \operatorname{dom} f$ and $C a$ nonempty, closed, and convex subset of int $\operatorname{dom} f$. If $\widehat{x} \in C$, then the following conditions are equivalent.

(i) The vector $\widehat{x}$ is the Bregman projection of $x$ onto $C$ with respect to $f$.

(ii) The vector $\hat{x}$ is the unique solution of the variational inequality.

$$
\langle\nabla f(x)-\nabla f(z), z-y\rangle \geq 0, \quad \forall y \in C .
$$

(iii) The vector $\widehat{x}$ is the unique solution of the inequality

$$
D_{f}(y, z)+D_{f}(z, x) \leq D_{f}(y, x), \quad \forall y \in C .
$$

Lemma 5 (see [6]). Let $f: E \rightarrow \mathbb{R}$ be a Gâteaux differentiable and totally convex function. If $x_{0} \in E$ and the sequence $\left\{D_{f}\left(x_{n}, x_{0}\right)\right\}_{n=1}^{\infty}$ is bounded, then the sequence $\left\{x_{n}\right\}_{n=1}^{\infty}$ is also bounded.

Lemma 6 (see [3]). Let $f: E \rightarrow(-\infty,+\infty)$ be a coercive (i.e., $\lim _{\|x\| \rightarrow \infty}(f(x) /\|x\|)=+\infty$ ) and Gâteaux differentiable function. Let $C$ be a closed and convex subset of $E$. If the bifunction $g: C \times C \rightarrow \mathbb{R}$ satisfies conditions (C1)-(C4), then

(1) $\operatorname{Res}_{g}^{f}$ is single-valued;

(2) $\operatorname{Res}_{g}^{f}$ is a Bregman firmly nonexpansive mapping;

(3) the set of fixed points of $\operatorname{Res}_{g}^{f}$ is the solution set of the equilibrium problem, that is, $F\left(\operatorname{Res}_{g}^{f}\right)=\mathrm{EP}(g)$;

(4) $\mathrm{EP}(g)$ is a closed and convex subset of $C$;

(5) for all $x \in E$ and $u \in F\left(\operatorname{Res}_{g}^{f}\right)$, one has

$$
\begin{gathered}
D_{f}\left(u, \operatorname{Res}_{g}^{f}(x)\right)+D_{f}\left(\operatorname{Res}_{g}^{f}(x), x\right) \\
\leq D_{f}(u, x) .
\end{gathered}
$$

\section{Main Results}

Now, we give our main theorems. 
Theorem 7. Let $E$ be a reflexive Banach space and $f: E \rightarrow$ $\mathbb{R}$ a coercive Legendre function which is bounded, uniformly Fréchet differentiable, and totally convex on bounded subsets of $E$. Let $K$ be a nonempty, closed, and convex subset of int $\operatorname{dom} f$ and $\left\{T_{i}\right\}_{i=1}^{\infty}: K \rightarrow K$ a countable family of closed Bregman asymptotically quasi-nonexpansive mappings with the sequences $\left\{k_{i, n}\right\} \subset[1, \infty)$ such that $\lim _{n \rightarrow \infty} k_{i, n}=1$ for every $i \geq 1$. Let $k_{n}=\sup \left\{k_{i, n}: i \geq 1\right\}$ and suppose that $\lim _{n \rightarrow \infty} k_{n}=1$. Let $g: K \times K \rightarrow \mathbb{R}$ be a bifunction satisfying conditions (C1)-(C4). Assume that each $T_{i}(i \geq 1)$ is uniformly asymptotically regular and $\Omega=\left[\bigcap_{i=1}^{\infty} F\left(T_{i}\right)\right] \cap \mathrm{EP}(g)$ is nonempty and bounded. Let $\left\{\alpha_{i, n}\right\}$ be a real sequence in $(0,1)$ with $\sum_{i=1}^{n} \alpha_{i, n}=1$ for every $n \geq 1$ and $\liminf _{n \rightarrow \infty} \alpha_{i, n}>0$ for every $i \geq 1$. Let $\left\{x_{n}\right\}$ be a sequence generated by the following manner:

$$
x_{1}=x \in K \text { chosen arbitrarily, }
$$

$u_{i, n} \in K$ such that

$$
\begin{gathered}
g\left(u_{i, n}, y\right)+\left\langle\nabla f\left(u_{i, n}\right)-\nabla f\left(T_{i}^{n} x_{n}\right), y-u_{i, n}\right\rangle \geq 0, \\
\forall y \in K, i=1, \ldots, n, \\
C_{n}=\left\{z \in K: \sum_{i=1}^{n} \alpha_{i, n} D_{f}\left(z, u_{i, n}\right)\right. \\
\left.\leq D_{f}\left(z, x_{n}\right)+\left(k_{n}-1\right) M_{n}\right\}, \\
D_{n}=\bigcap_{i=1}^{n} C_{i}, \\
x_{n+1}=\operatorname{proj}_{D_{n}}^{f} x, \quad n=1,2, \ldots,
\end{gathered}
$$

where $M_{n}=\sup \left\{D_{f}\left(v, x_{n}\right): v \in \Omega\right\}$ for each $n \geq 1$. Then, $\left\{x_{n}\right\}$ defined by (30) converges strongly to proj $_{\Omega}^{f} x$ as $n \rightarrow \infty$.

Proof. First, we prove that the sequence $\left\{x_{n}\right\}$ is well defined. Note that

$$
\sum_{i=1}^{n} \alpha_{i, n} D_{f}\left(z, u_{i, n}\right) \leq D_{f}\left(z, x_{n}\right)+\left(k_{n}-1\right) M_{n}
$$

is

$$
\begin{aligned}
& \sum_{i=1}^{n} \alpha_{i, n}\left(f(z)-f\left(u_{i, n}\right)-\left\langle\nabla f\left(u_{i, n}\right), z-u_{i, n}\right\rangle\right) \\
& \quad \leq f(z)-f\left(x_{n}\right)-\left\langle\nabla f\left(x_{n}\right), z-x_{n}\right\rangle+\left(k_{n}-1\right) M_{n}
\end{aligned}
$$

that is,

$$
\begin{aligned}
f\left(x_{n}\right) & -\sum_{i=1}^{n} \alpha_{i, n} f\left(u_{i, n}\right)+\left\langle\nabla f\left(x_{n}\right), z-x_{n}\right\rangle \\
& \leq \sum_{i=1}^{n} \alpha_{i, n}\left\langle\nabla f\left(u_{i, n}\right), z-u_{i, n}\right\rangle+\left(k_{n}-1\right) M_{n} .
\end{aligned}
$$

This shows that $C_{n}$ is closed and convex for every $n \geq 1$. From the definition of $D_{n}$, it is easy to see that $D_{n}$ is closed and convex for every $n \geq 1$. For every $i \geq 1$ and $n \geq 1$, Lemma 6 shows that $u_{i, n}=\operatorname{Res}_{g}^{f} T_{i}^{n} x_{n}$ and $D_{f}\left(v, \operatorname{Res}_{g}^{f} y\right) \leq D_{f}(v, y)$ for any $v \in \Omega$ and $y \in E$. Hence,

$$
\begin{aligned}
D_{f}\left(v, u_{i, n}\right) & =D_{f}\left(v, \operatorname{Res}_{g}^{f} T_{i}^{n} x_{n}\right) \\
& \leq D_{f}\left(v, T_{i}^{n} x_{n}\right) \\
& \leq k_{i, n} D_{f}\left(v, x_{n}\right) \\
& \leq k_{n} D_{f}\left(v, x_{n}\right) \\
& =D_{f}\left(v, x_{n}\right)+\left(k_{n}-1\right) D_{f}\left(v, x_{n}\right) \\
& \leq D_{f}\left(v, x_{n}\right)+\left(k_{n}-1\right) M_{n} .
\end{aligned}
$$

Since $\sum_{i=1}^{n} \alpha_{i, n}=1$ for every $n \geq 1$, we have

$$
\begin{aligned}
\sum_{i=1}^{n} \alpha_{i, n} & D_{f}\left(v, u_{i, n}\right) \\
& \leq \sum_{i=1}^{n} \alpha_{i, n}\left(D_{f}\left(v, x_{n}\right)+\left(k_{n}-1\right) M_{n}\right) \\
& =D_{f}\left(v, x_{n}\right)+\left(k_{n}-1\right) M_{n} .
\end{aligned}
$$

This shows that $v \in C_{n}$ for every $n \geq 1$. Thus $\Omega \subset C_{n}$ for every $n \geq 1$. Further, we have $\Omega \subset D_{n}$ for every $n \geq 1$. Thus the sequence $\left\{x_{n}\right\}$ is well defined.

From proj $_{D_{n}}^{f} x=x_{n+1}$, by Lemma 4(iii) we have

$$
\begin{aligned}
D_{f}\left(x_{n+1}, x\right) & =D_{f}\left(\operatorname{proj}_{D_{n}}^{f} x, x\right) \\
& \leq D_{f}(v, x)-D_{f}\left(v, \operatorname{proj}_{D_{n}}^{f} x\right) \\
& \leq D_{f}(v, x)
\end{aligned}
$$

for any $v \in \Omega$. Hence the sequence $D_{f}\left(x_{n}, x\right)$ is bounded. Therefore by Lemma 5 the sequence $\left\{x_{n}\right\}$ is bounded.

On the other hand, in view of $x_{n+1}=\operatorname{proj}_{D_{n}}^{f} x$ and $x_{n+2}=$ $\operatorname{proj}_{D_{n+1}}^{f} x \in D_{n+1} \subset D_{n}$, from Lemma 4(iii) we have

$$
D_{f}\left(x_{n+2}, \operatorname{proj}_{D_{n}}^{f} x\right)+D_{f}\left(\operatorname{proj}_{D_{n}}^{f} x, x\right) \leq D_{f}\left(x_{n+2}, x\right),
$$

that is,

$$
D_{f}\left(x_{n+2}, x_{n+1}\right)+D_{f}\left(x_{n+1}, x\right) \leq D_{f}\left(x_{n+2}, x\right) .
$$

Therefore the sequence $\left\{D_{f}\left(x_{n}, x\right)\right\}$ is increasing, and since it is also bounded, $\lim _{n \rightarrow \infty} D_{f}\left(x_{n}, x\right)$ exists. By the construction of $D_{n}$, we have that $D_{m} \subset D_{n}$ and $x_{m}=\operatorname{proj}_{D_{m-1}}^{f} x \in$ $D_{m-1} \subset D_{n-1}$ for any positive integer $m \geq n$. It follows that

$$
\begin{aligned}
D_{f}\left(x_{m}, x_{n}\right) & =D_{f}\left(x_{m}, \operatorname{proj}_{D_{n-1}}^{f} x\right) \\
& \leq D_{f}\left(x_{m}, x\right)-D_{f}\left(\operatorname{proj}_{D_{n-1}}^{f} x, x\right) \\
& =D_{f}\left(x_{m}, x\right)-D_{f}\left(x_{n}, x\right) .
\end{aligned}
$$


Letting $m, n \rightarrow \infty$ in (39), we see that $D_{f}\left(x_{m}, x_{n}\right) \rightarrow 0$. It follows from Lemma 3 that $x_{m}-x_{n} \rightarrow 0$ as $m, n \rightarrow \infty$. Hence, $\left\{x_{n}\right\}$ is a Cauchy sequence. Since $E$ is a Banach space and $K$ is closed and convex, we can assume that

$$
\lim _{n \rightarrow \infty} x_{n}=x^{*} \in K
$$

By taking $m=n+1$ in (39), we see that

$$
\lim _{n \rightarrow \infty} D_{f}\left(x_{n+1}, x_{n}\right)=0 \text {. }
$$

Lemma 3 implies that

$$
\lim _{n \rightarrow \infty}\left\|x_{n+1}-x_{n}\right\|=0
$$

Since $x_{n+1}=\operatorname{proj}_{D_{n}}^{f} x \in D_{n} \subset C_{n}$, we have

$$
\sum_{i=1}^{n} \alpha_{i, n} D_{f}\left(x_{n+1}, u_{i, n}\right) \leq D_{f}\left(x_{n+1}, x_{n}\right)+\left(k_{n}-1\right) M_{n} .
$$

Then (41) implies that

$$
\lim _{n \rightarrow \infty} \sum_{i=1}^{n} \alpha_{i, n} D_{f}\left(x_{n+1}, u_{i, n}\right)=0
$$

Note that $\alpha_{i, n} D_{f}\left(x_{n+1}, u_{i, n}\right) \leq \sum_{i=1}^{n} \alpha_{i, n} D_{f}\left(x_{n+1}, u_{i, n}\right)$ and $\liminf _{n \rightarrow \infty} \alpha_{i, n}>0$, we have

$$
\lim _{n \rightarrow \infty} D_{f}\left(x_{n+1}, u_{i, n}\right)=0
$$

for every $i \geq 1$. It follows from Lemma 3 that

$$
\lim _{n \rightarrow \infty}\left\|x_{n+1}-u_{i, n}\right\|=0
$$

for every $i \geq 1$. Note that

$$
\left\|u_{i, n}-x_{n}\right\| \leq\left\|u_{i, n}-x_{n+1}\right\|+\left\|x_{n+1}-x_{n}\right\| .
$$

Combining (42) with (46), we see that

$$
\lim _{n \rightarrow \infty}\left\|u_{i, n}-x_{n}\right\|=0
$$

for every $i \geq 1$. This means that the sequence $\left\{u_{i, n}\right\}$ is bounded. Since $f$ is uniformly Fréchet differentiable, it follows from Lemma 2 that

$$
\lim _{n \rightarrow \infty}\left\|\nabla f\left(u_{i, n}\right)-\nabla f\left(x_{n}\right)\right\|_{*}=0 .
$$

Since $f$ is uniformly Fréchet differentiable, it is also uniformly continuous (see [19, Theorem 1.8, p.13]) and therefore

$$
\lim _{n \rightarrow \infty}\left\|f\left(u_{i, n}\right)-f\left(x_{n}\right)\right\|=0
$$

From the definition of the Bregman distance, we obtain that for every

$$
\begin{aligned}
& D_{f}\left(v, x_{n}\right)-D_{f}\left(v, u_{i, n}\right) \\
&=\left[f(v)-f\left(x_{n}\right)-\left\langle\nabla f\left(x_{n}\right), v-x_{n}\right\rangle\right] \\
& \quad-\left[f(v)-f\left(u_{i, n}\right)-\left\langle\nabla f\left(u_{n}\right), v-u_{i, n}\right\rangle\right] \\
&=f\left(u_{i, n}\right)-f\left(x_{n}\right)+\left\langle\nabla f\left(u_{i, n}\right), v-u_{i, n}\right\rangle \\
&-\left\langle\nabla f\left(x_{n}\right), v-x_{n}\right\rangle \\
&= f\left(u_{i, n}\right)-f\left(x_{n}\right) \\
&+\left\langle\nabla f\left(u_{i, n}\right), x_{n}-u_{i, n}\right\rangle \\
&+\left\langle\nabla f\left(u_{i, n}\right)-\nabla f\left(x_{n}\right), v-x_{n}\right\rangle
\end{aligned}
$$

for any $v \in \Omega$. Since every sequence $\left\{u_{i, n}\right\}$ is bounded, $\left\{\nabla f\left(u_{i, n}\right)\right\}$ is also bounded for every $i \geq 1$. Now from (48)(50), we have

$$
\lim _{n \rightarrow \infty} D_{f}\left(v, x_{n}\right)-D_{f}\left(v, u_{i, n}\right)=0
$$

for any $v \in \Omega$ and for every $i \geq 1$.

In view of $u_{i, n}=\operatorname{Res}_{g}^{f} T_{i}^{n} x_{n}$, by Lemma 6 (5) we have

$$
\begin{aligned}
D_{f}\left(u_{i, n}, T_{i}^{n} x_{n}\right) & =D_{f}\left(\operatorname{Res}_{g}^{f} T_{i}^{n} x_{n}, T_{i}^{n} x_{n}\right) \\
& \leq D_{f}\left(v, T^{n} x_{n}\right)-D_{f}\left(v, \operatorname{Res}_{g}^{f} T_{i}^{n} x_{n}\right) \\
& \leq k_{n} D_{f}\left(v, x_{n}\right)-D_{f}\left(v, \operatorname{Res}_{g}^{f} T_{i}^{n} x_{n}\right) \\
& \leq D_{f}\left(v, x_{n}\right)+\left(k_{n}-1\right) M_{n}-D_{f}\left(v, u_{i, n}\right) .
\end{aligned}
$$

Note that $M_{n}$ is bounded and $k_{n} \rightarrow 1$ as $n \rightarrow \infty$. It follows from (52) that

$$
\lim _{n \rightarrow \infty} D_{f}\left(u_{i, n}, T_{i}^{n} x_{n}\right)=0
$$

for every $i \geq 1$. Lemma 3 shows that

$$
\lim _{n \rightarrow \infty}\left\|u_{i, n}-T_{i}^{n} x_{n}\right\|=0 .
$$

Note that $\left\|T_{i}^{n} x_{n}-x_{n}\right\| \leq\left\|T_{i}^{n} x_{n}-u_{i, n}\right\|+\left\|u_{i, n}-x_{n}\right\|$. From (48) and (55) we get

$$
\lim _{n \rightarrow \infty}\left\|T_{i}^{n} x_{n}-x_{n}\right\|=0
$$

for every $i \geq 1$. Note that

$$
\left\|T_{i}^{n} x_{n}-x^{*}\right\| \leq\left\|T_{i}^{n} x_{n}-x_{n}\right\|+\left\|x_{n}-x^{*}\right\| .
$$

It follows from (40) and (56) that

$$
\lim _{n \rightarrow \infty}\left\|T_{i}^{n} x_{n}-x^{*}\right\|=0
$$

for every $i \geq 1$. On the other hand, we have

$$
\left\|T_{i}^{n+1} x_{n}-x^{*}\right\| \leq\left\|T_{i}^{n+1} x_{n}-T_{i}^{n} x_{n}\right\|+\left\|T_{i}^{n} x_{n}-x^{*}\right\| .
$$


Since every $T_{i}$ is uniformly asymptotically regular and (58), we obtain that, for every $i \geq 1$,

$$
\lim _{n \rightarrow \infty}\left\|T_{i}^{n+1} x_{n}-x^{*}\right\|=0
$$

that is, $T_{i} T_{i}^{n} x_{n} \rightarrow x^{*}$ as $n \rightarrow \infty$. From the closedness of $T_{i}$, we see that $x^{*} \in F\left(T_{i}\right)$ for every $i \geq 1$. Thus $x^{*} \in \bigcap_{i=1}^{\infty} F\left(T_{i}\right)$.

Next we prove that $x^{*} \in \operatorname{EP}(g)$ for every $i \geq 1$. Since $f$ is uniformly Fréchet differentiable, $\nabla f$ is uniformly continuous. Thus, by (55) we have

$$
\lim _{n \rightarrow \infty}\left(\nabla f\left(u_{i, n}\right)-\nabla f\left(T_{i}^{n} x_{n}\right)\right)=0 .
$$

Since $u_{i, n}=\operatorname{Res}_{g}^{f} T_{i}^{n} x_{n}$, we have

$$
\begin{gathered}
g\left(u_{i, n}, y\right)+\left\langle\nabla f\left(u_{i, n}\right)-\nabla f\left(T_{i}^{n} x_{n}\right), y-u_{i, n}\right\rangle \\
\geq 0, \quad \forall y \in K .
\end{gathered}
$$

We have from (C2) that

$$
\begin{gathered}
\left\langle\nabla f\left(u_{i, n}\right)-\nabla f\left(T_{i}^{n} x_{n}\right), y-u_{i, n}\right\rangle \\
\geq-g\left(u_{i, n}, y\right) \\
\geq g\left(y, u_{i, n}\right), \quad \forall y \in K .
\end{gathered}
$$

Letting $n \rightarrow \infty$, we have from (61) and (C4) that

$$
g\left(y, x^{*}\right) \leq 0, \quad \forall y \in K .
$$

For $t$ with $0<t \leq 1$ and $y \in K$, let $y_{t}=t y+(1-t) x^{*}$. Since $y \in K$ and $x^{*} \in K$, we have $y_{t} \in K$ and hence $g\left(y_{t}, x^{*}\right) \leq 0$. So, from (C1) we have

$$
\begin{aligned}
0 & =g\left(y_{t}, y_{t}\right) \\
& \leq \operatorname{tg}\left(y_{t}, y\right)+(1-t) g\left(y_{t}, x^{*}\right) \\
& \leq \operatorname{tg}\left(y_{t}, y\right) .
\end{aligned}
$$

Dividing by $t$, we have

$$
g\left(y_{t}, y\right) \geq 0, \quad \forall y \in K
$$

Letting $t \downarrow 0$, from (C3) we have

$$
g\left(x^{*}, y\right) \geq 0, \quad \forall y \in K
$$

Therefore, $x^{*} \in \operatorname{EP}(g)$. Thus $x^{*} \in \cap_{i=1}^{\infty} \operatorname{EP}(g)$.

Finally, we show that $x^{*}=\operatorname{proj}_{\Omega} x$. Since $\Omega \subset D_{n}$ for every $n \geq 1$, by Lemma 4(ii) we arrive at

$$
\left\langle x_{n}-v, \nabla f(x)-\nabla f\left(x_{n}\right)\right\rangle \geq 0, \quad \forall v \in \Omega .
$$

Taking the limit as $n \rightarrow \infty$ in (68), we obtain that

$$
\left\langle x^{*}-v, \nabla f(x)-\nabla f\left(x^{*}\right)\right\rangle \geq 0, \quad \forall v \in \Omega
$$

and hence $x^{*}=\operatorname{proj}_{\Omega} x$ by Lemma 4(ii). This completes the proof.
Corollary 8. Let $E$ be a reflexive Banach space and $f: E \rightarrow$ $\mathbb{R}$ a coercive Legendre function which is bounded, uniformly Fréchet differentiable and totally convex on bounded subsets of E. Let $K$ be a nonempty, closed, and convex subset of int dom $f$ and $T: K \rightarrow K$ a closed Bregman asymptotically quasinonexpansive mapping with the sequence $\left\{k_{n}\right\} \subset[1, \infty)$ such that $\lim _{n \rightarrow \infty} k_{n}=1$. Let $g: K \times K \rightarrow \mathbb{R}$ be a bifunction satisfying conditions (C1)-(C4). Assume that $T$ is uniformly asymptotically regular and $\Omega=F(T) \cap \operatorname{EP}(g)$ is nonempty and bounded. Let $\left\{x_{n}\right\}$ be a sequence generated by the following manner:

$x \in K$ chosen arbitrarily,

$u_{n} \in K$ such that

$$
\begin{gathered}
g\left(u_{n}, y\right)+\left\langle\nabla f\left(u_{n}\right)-\nabla f\left(T^{n} x_{n}\right), y-u_{n}\right\rangle \\
\geq 0, \quad \forall y \in K, \\
C_{n}=\left\{z \in K: D_{f}\left(z, u_{n}\right) \leq D_{f}\left(z, x_{n}\right)+\left(k_{n}-1\right) M_{n}\right\}, \\
D_{n}=\bigcap_{i=1}^{n} C_{i}, \\
x_{n+1}=\operatorname{proj}_{D_{n}}^{f} x, \quad n=1,2, \ldots,
\end{gathered}
$$

where $M_{n}=\sup \left\{D_{f}\left(v, x_{n}\right): v \in \Omega\right\}$ for each $n \geq 1$. Then, $\left\{x_{n}\right\}$ defined by (70) converges strongly to $\operatorname{proj}_{\Omega}^{f} x$ as $n \rightarrow \infty$.

Since every Bregman quasi-nonexpansive mapping is Bregman quasi-asymptotically nonexpansive, we have the following results.

Corollary 9. Let $E$ be a reflexive Banach space and let $f$ : $E \rightarrow \mathbb{R}$ be a coercive Legendre function which is bounded, uniformly Fréchet differentiable, and totally convex on bounded subsets of E. Let $K$ be a nonempty, closed, and convex subset of int dom $f$. Let $\left\{T_{i}\right\}_{i=1}^{\infty}: K \rightarrow K$ be a countable family of closed Bregman quasi-nonexpansive mappings and $g: K \times K \rightarrow \mathbb{R}$ a bifunction satisfying conditions (C1)-(C4). Assume that $\Omega=$ $\left[\cap_{i=1}^{\infty} F\left(T_{i}\right)\right] \bigcap \operatorname{EP}(g) \neq \emptyset$. Let $\left\{\alpha_{i, n}\right\}$ be a real sequence in $(0,1)$ with $\sum_{i=1}^{n} \alpha_{i, n}=1$ and $\liminf _{n \rightarrow \infty} \alpha_{i, n}>0$ for every $i \geq 1$. Let $\left\{x_{n}\right\}$ be a sequence generated by the following manner:

$$
x \in K \text { chosen arbitrarily, }
$$

$u_{i, n} \in K$ such that

$$
\begin{aligned}
& g\left(u_{i, n}, y\right)+\left\langle\nabla f\left(u_{i, n}\right)-\nabla f\left(T_{i}^{n} x_{n}\right), y-u_{i, n}\right\rangle \\
\geq & 0, \quad \forall y \in K, i=1, \ldots, n, \\
C_{n}= & \left\{z \in K: \sum_{i=1}^{n} \alpha_{i, n} D_{f}\left(z, u_{i, n}\right) \leq D_{f}\left(z, x_{n}\right)\right\},
\end{aligned}
$$




$$
\begin{gathered}
D_{n}=\bigcap_{i=1}^{n} C_{i}, \\
x_{n+1}=\operatorname{proj}_{D_{n}}^{f} x, \quad n=1,2, \ldots .
\end{gathered}
$$

Then, $\left\{x_{n}\right\}$ defined by (71) converges strongly to $\operatorname{proj}_{\Omega}^{f} x$ as $n \rightarrow$ $\infty$.

Corollary 10. Let $E$ be a reflexive Banach space and let $f$ : $E \rightarrow \mathbb{R}$ be a coercive Legendre function which is bounded, uniformly Fréchet differentiable, and totally convex on bounded subsets of $E$. Let $K$ be a nonempty, closed, and convex subset of int $\operatorname{dom} f$. Let $T: K \rightarrow K$ be a closed Bregman quasinonexpansive mapping and $g: K \times K \rightarrow \mathbb{R}$ a bifunction satisfying conditions (C1)-(C4). Assume that $\Omega=F(T) \cap$ $\operatorname{EP}(g) \neq \emptyset$. Let $\left\{x_{n}\right\}$ be a sequence generated by the following manner:

$$
x \in K \text { chosen arbitrarily, }
$$

$u_{n} \in K$ such that

$$
\begin{gathered}
g\left(u_{n}, y\right)+\left\langle\nabla f\left(u_{n}\right)-\nabla f\left(T^{n} x_{n}\right), y-u_{n}\right\rangle \geq 0, \\
\forall y \in K, \\
C_{n}=\left\{z \in K: D_{f}\left(z, u_{n}\right) \leq D_{f}\left(z, x_{n}\right)\right\}, \\
D_{n}=\bigcap_{i=1}^{n} C_{i}, \\
x_{n+1}=\operatorname{proj}_{D_{n}}^{f} x, \quad n=1,2, \ldots
\end{gathered}
$$

Then, $\left\{x_{n}\right\}$ defined by (72) converges strongly to $\operatorname{proj}_{\Omega}^{f} x$ as $n \rightarrow$ $\infty$

Remark 11. Set $\alpha_{n, i}=1 / i(i+1)+1 / n(n+1)$ for each $n \geq 1$ and $i=1,2, \ldots, n$ and $k_{i, n}=1+1 /$ in for each $n \geq 1$ and $i \geq 1$. Then $\sum_{i=1}^{n} \alpha_{i, n}=1$ and $\liminf _{n \rightarrow \infty} \alpha_{i, n}=1 / i(i+1)>0$. Also, $k_{n}=\sup \left\{k_{i, n}: i \geq 1\right\}=1$ for every $n \geq 1$. Hence, $\left\{\alpha_{i, n}\right\}$ and $\left\{k_{i, n}\right\}$ satisfy the conditions of Theorem 7 .

Remark 12. It needs to notice that Corollaries 9 and 10 still hold if we replace the closedness of the mappings with $\widehat{F}(T)=$ $F(T)$.

In the equilibrium problem, the bifunction $g$ is usually required to satisfy conditions $(\mathrm{C} 1)-(\mathrm{C} 4)$. But, if the condition (C3) is replaced with the following condition:

$\left(\mathrm{C} 3^{\prime}\right)$ for every fixed $y \in C, g(\cdot, y)$ is continuous, then we have the following result:

Lemma 13. Let $f: E \rightarrow(-\infty,+\infty)$ be a coercive (i.e., $\left.\lim _{\|x\| \rightarrow \infty}(f(x) /\|x\|)=+\infty\right)$ and Gâteaux differentiable function. Let $C$ be a closed and convex subset of $E$. If the bifunction $g: C \times C \rightarrow \mathbb{R}$ satisfies conditions (C1), (C2), $\left(C 3^{\prime}\right)$, and (C4), then the mapping $\operatorname{Res}_{g}^{f}$ defined by (2.2) is closed.
Proof. Let $\left\{x_{n}\right\} \subset E$ converge to $x^{\prime}$ and $\left\{\operatorname{Res}_{g}^{f} x_{n}\right\}$ to $\widehat{x}$. To end the conclusion, we need to prove that $\operatorname{Res}_{g}^{f} x^{\prime}=\widehat{x}$. Indeed, for each $x_{n}$, Lemma 6 shows that there exists a unique $z_{n} \in C$ such that $z_{n}=\operatorname{Res}_{g}^{f} x_{n}$, that is,

$$
g\left(z_{n}, y\right)+\left\langle\nabla f\left(z_{n}\right)-\nabla f\left(x_{n}\right), y-z_{n}\right\rangle \geq 0, \quad \forall y \in C
$$

Since $f$ is uniformly Fréchet differentiable, $\nabla f$ is uniformly continuous. So, taking the limit as $n \rightarrow \infty$ in (73), by using $\left(\mathrm{C}^{\prime}\right)$ we get

$$
g(\widehat{x}, y)+\left\langle\nabla f(\widehat{x})-\nabla f\left(x^{\prime}\right), y-\widehat{x}\right\rangle \geq 0, \quad \forall y \in C,
$$

which implies that $\operatorname{Res}_{g}^{f} x^{\prime}=\widehat{x}$. This completes the proof.

If the bifunction $g$ satisfies conditions (C1), (C2), (C3'), and $(\mathrm{C} 4)$ instead of $(\mathrm{C} 1)-(\mathrm{C} 4)$, then we have a simple method to prove that $x^{*} \in \mathrm{EP}(g)$ in the proof of Theorem 7. Indeed, from the proof of Theorem 7 , we see that

$$
\begin{gathered}
u_{i, n}-T_{i}^{n} x_{n} \longrightarrow 0, \quad \text { that is, } \operatorname{Res}_{g}^{f} T_{i}^{n} x_{n}-T_{i}^{n} x_{n} \longrightarrow 0, \\
T_{i}^{n} x_{n}-x_{n} \longrightarrow 0 \quad \text { as } n \longrightarrow \infty, \forall i \geq 1
\end{gathered}
$$

Note that $x_{n} \rightarrow x^{*}$ as $n \rightarrow \infty$. This shows that $T_{i}^{n} x_{n} \rightarrow$ $x^{*}$ as $n \rightarrow \infty$ for every $i \geq 1$. It follows from the closedness of $\operatorname{Res}_{g}^{f}$ that $x^{*} \in F\left(\operatorname{Res}_{g}^{f}\right)$. Lemma 6 shows that $x^{*} \in \operatorname{EP}(g)$.

Remark 14. Obviously, the proof process of $x^{*} \in \operatorname{EP}(g)$ is simple if we replace condition (C3) with $\left(\mathrm{C} 3^{\prime}\right)$ which is such that $\operatorname{Res}_{g}^{f}$ is closed. In fact, although condition $\left(\mathrm{C}^{\prime}\right)$ is stronger than (C3), it is not easier to verify condition (C3) than to verify the condition $\left(\mathrm{C} 3^{\prime}\right)$. Hence, from this viewpoint, the condition $\left(\mathrm{C}^{\prime}\right)$ is acceptable.

\section{Acknowledgments}

This work is supported by the Fundamental Research Fundsfor the Central Universities (Grant Number: 13MS109) and the HeBei Education 4 Department (Grant Number: 936101101).

\section{References}

[1] K. Nakajo and W. Takahashi, "Strong convergence theorems for nonexpansive mappings and nonexpansive semigroups," Journal of Mathematical Analysis and Applications, vol. 279, no. 2, pp. 372-379, 2003.

[2] W. Takahashi, Y. Takeuchi, and R. Kubota, "Strong convergence theorems by hybrid methods for families of nonexpansive mappings in Hilbert spaces," Journal of Mathematical Analysis and Applications, vol. 341, no. 1, pp. 276-286, 2008.

[3] S. Reich and S. Sabach, "Two strong convergence theorems for Bregman strongly nonexpansive operators in reflexive Banach spaces," Nonlinear Analysis. Theory, Methods \& Applications A, vol. 73, no. 1, pp. 122-135, 2010. 
[4] H. H. Bauschke and P. L. Combettes, "Construction of best Bregman approximations in reflexive Banach spaces," Proceedings of the American Mathematical Society, vol. 131, no. 12, pp. 3757-3766, 2003.

[5] F. Kohsaka and W. Takahashi, "Proximal point algorithms with Bregman functions in Banach spaces," Journal of Nonlinear and Convex Analysis, vol. 6, no. 3, pp. 505-523, 2005.

[6] S. Reich and S. Sabach, "Two strong convergence theorems for a proximal method in reflexive Banach spaces," Numerical Functional Analysis and Optimization, vol. 31, no. 1-3, pp. 2244, 2010.

[7] S. Reich and S. Sabach, "A strong convergence theorem for a proximal-type algorithm in reflexive Banach spaces," Journal of Nonlinear and Convex Analysis, vol. 10, no. 3, pp. 471-485, 2009.

[8] S. Reich and S. Sabach, "A projection method for solving nonlinear problems in reflexive Banach spaces," Journal of Fixed Point Theory and Applications, vol. 9, no. 1, pp. 101-116, 2011.

[9] H. H. Bauschke, J. M. Borwein, and P. L. Combettes, "Essential smoothness, essential strict convexity, and Legendre functions in Banach spaces," Communications in Contemporary Mathematics, vol. 3, no. 4, pp. 615-647, 2001.

[10] J. F. Bonnans and A. Shapiro, Perturbation Analysis of Optimization Problems, Springer, New York, NY, USA, 2000.

[11] H. H. Bauschke and J. M. Borwein, "Legendre functions and the method of random Bregman projections," Journal of Convex Analysis, vol. 4, no. 1, pp. 27-67, 1997.

[12] Y. Censor and A. Lent, "An iterative row-action method for interval convex programming," Journal of Optimization Theory and Applications, vol. 34, no. 3, pp. 321-353, 1981.

[13] L. M. Bregman, "A relaxation method of finding a common point of convex sets and its application to the solution of problems in convex programming," USSR Computational Mathematics and Mathematical Physics, vol. 7, pp. 620-631, 1967.

[14] D. Butnariu and A. N. Iusem, Totally Convex Functions for Fixed Points Computation and Infinite Dimensional Optimization, Kluwer Academic Publishers, Dordrecht, The Netherlands, 2000.

[15] D. Butnariu and E. Resmerita, "Bregman distances, totally convex functions, and a method for solving operator equations in Banach spaces," Abstract and Applied Analysis, Article ID 84919, 39 pages, 2006.

[16] P. L. Combettes and S. A. Hirstoaga, "Equilibrium programming in Hilbert spaces," Journal of Nonlinear and Convex Analysis, vol. 6, no. 1, pp. 117-136, 2005.

[17] Y. Censor and S. Reich, "Iterations of paracontractions and firmly nonexpansive operators with applications to feasibility and optimization," Optimization, vol. 37, no. 4, pp. 323-339, 1996.

[18] S. Reich, "A weak convergence theorem for the alternating method with Bregman distances," in Theory and Applications of Nonlinear Operators of Accretive and Monotone Type, vol. 178, pp. 313-318, Marcel Dekker, New York, NY, USA, 1996.

[19] A. Ambrosetti and G. Prodi, A Primer of Nonlinear Analysis, Cambridge University Press, Cambridge, UK, 1993. 


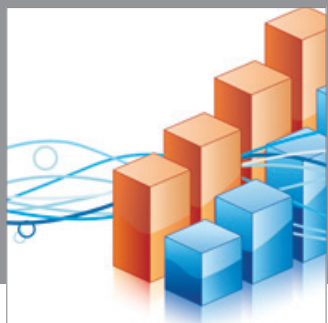

Advances in

Operations Research

mansans

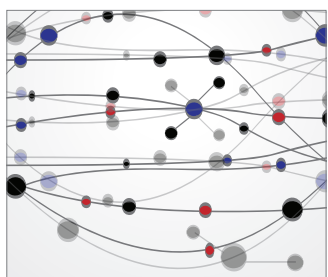

The Scientific World Journal
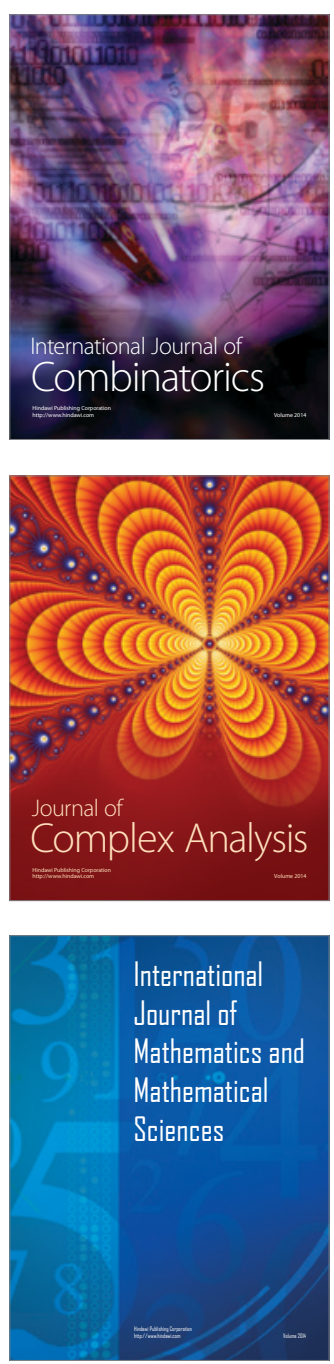
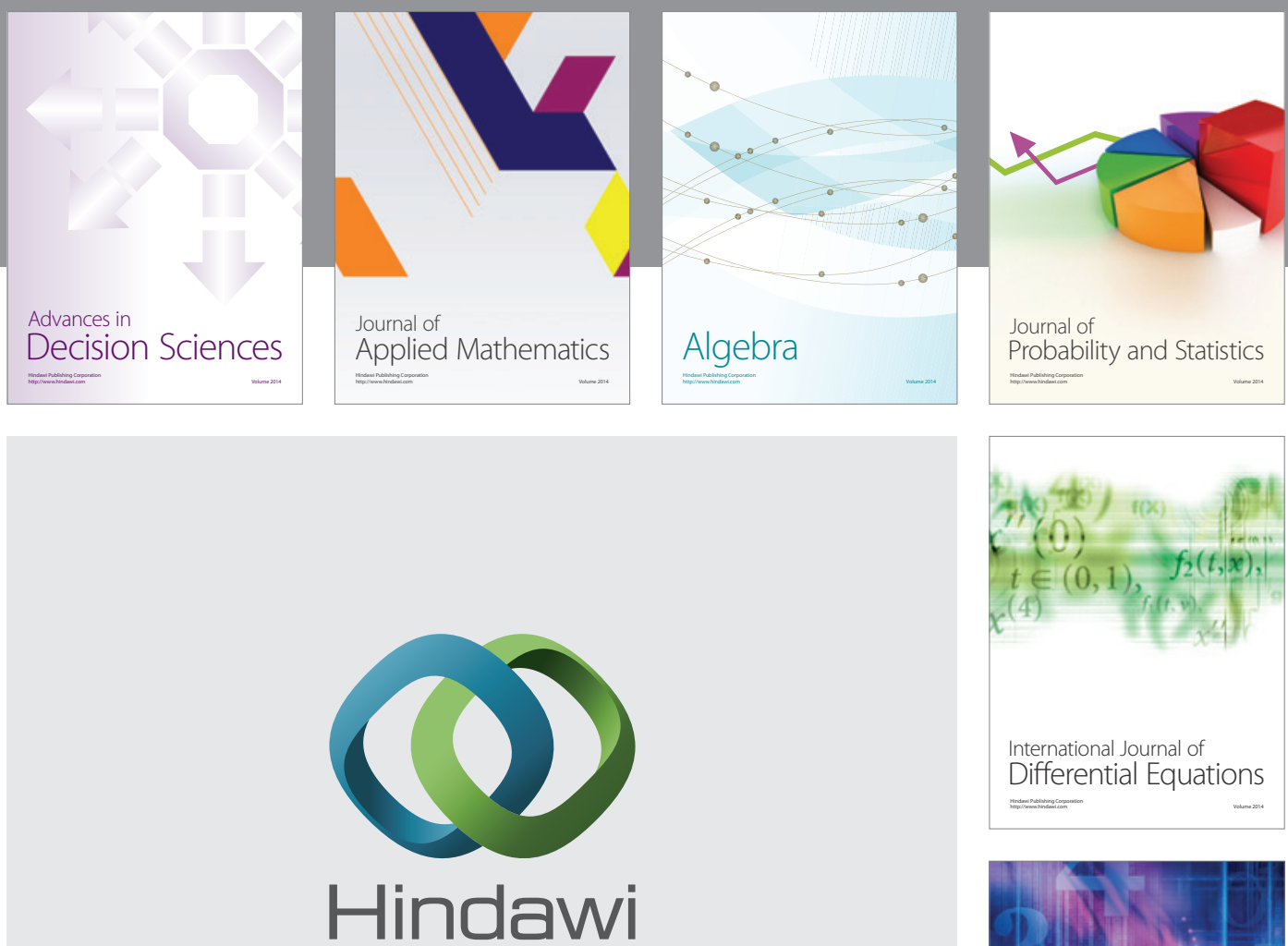

Submit your manuscripts at http://www.hindawi.com
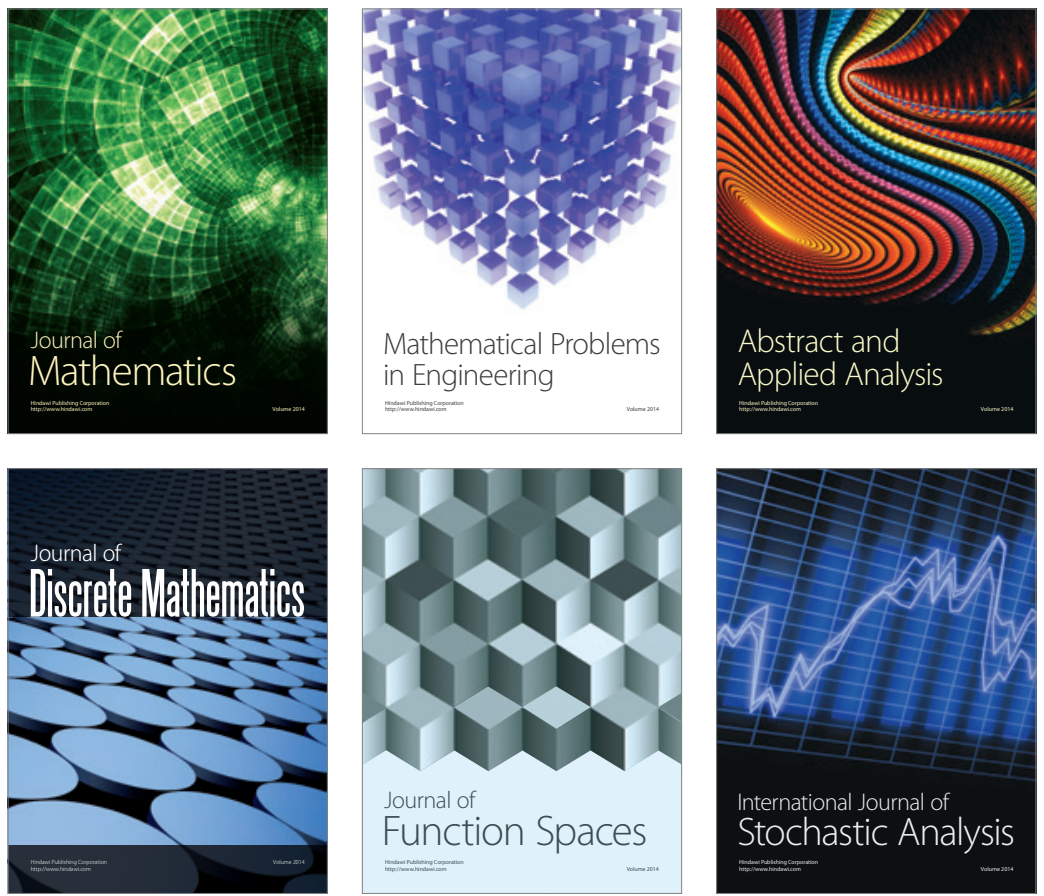

Journal of

Function Spaces

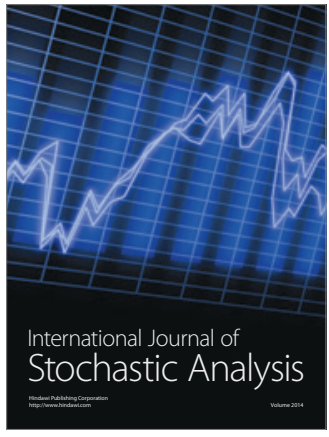

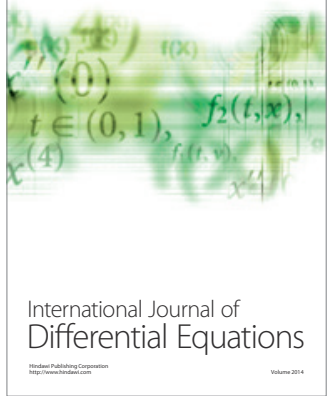
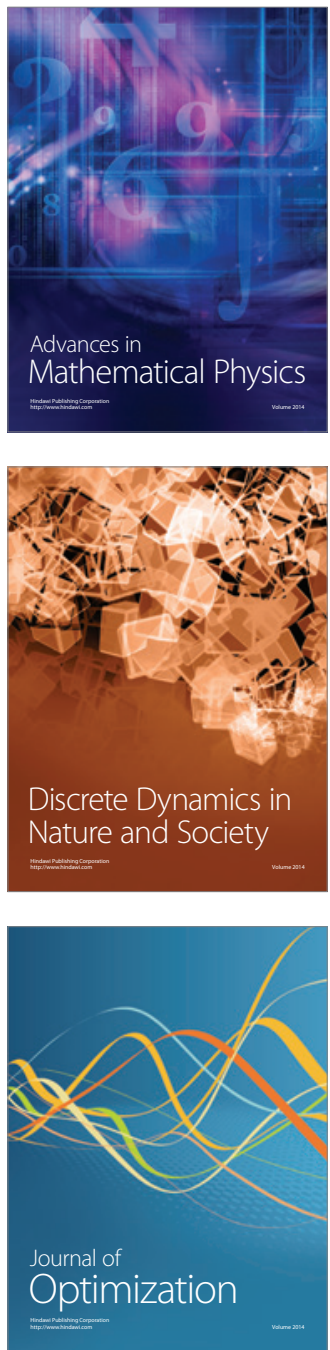